UCRL-JC-126223

PREPRINT

\title{
Dose Rate Effects During Damage Accumulation in Silicon
}

Maria J. Caturla

Tomas Diaz de la Rubia

This paper was prepared for submittal to the

1996 Fall Meeting of the

Materials Research Society

Boston, Massachusetts

December 2- 6, 1996

January 1997

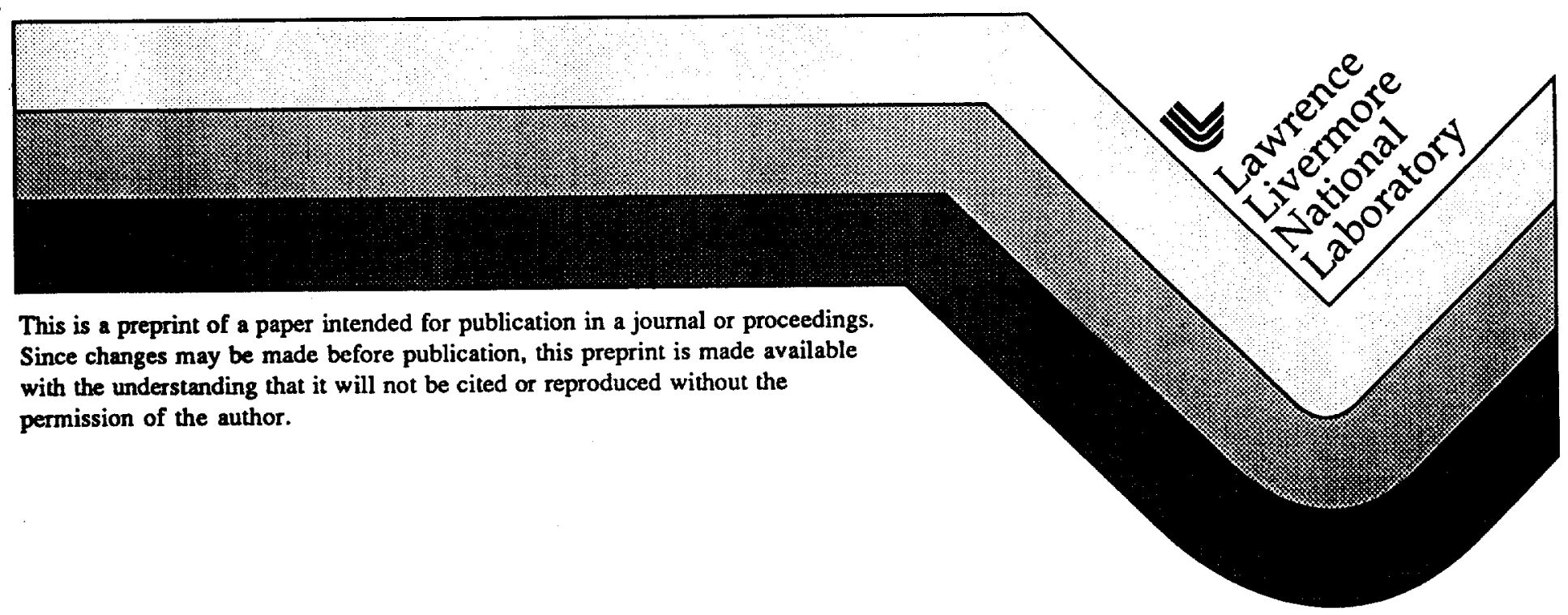




\section{DISCLAIMER}

This document was prepared as an account of work sponsored by an agency of the United States Government. Neither the United States Government nor the University of California nor any of their employees, makes any warranty, express or implied, or assumes any legal liability or responsibility for the accuracy, completeness, or usefulness of any information, apparatus, product, or process disclosed, or represents that its use would not infringe privately owned rights. Reference herein to any specific commercial product, process, or service by trade name, trademark, manufacturer, or otherwise, does not necessarily constitute or imply its endorsement, recommendation, or favoring by the United States Government or the University of California. The views and opinions of authors expressed herein do not necessarily state or reflect those of the United States Government or the University of California, and shall not be used for advertising or product endorsement purposes. 


\title{
Dose Rate Effects During Damage Accumulation in Silicon
}

\author{
M.-J. Caturla and T. Diaz de la Rubia \\ Lawrence Livermore National Laboratory, P.O. Box 808 Livermore, CA-94550
}

\begin{abstract}
We combine molecular dynamics and Monte Carlo simulations to study damage accumulation and dose rate effects during irradiation of Silicon. We obtain the initial stage of the damage produced by heavy and light ions using classical molecular dynamics simulations. While heavy ions like As or $\mathrm{Pt}$ induce amorphization by single ion impact, light ions like B only produce point defects or small clusters of defects. The amorphous pockets generated by heavy ions are stable below room temperature and recrystallize at temperatures below the threshold for recrystallization of a planar amorphous-crystalline interface. The damage accumulation during light ion irradiation is simulated using a Monte Carlo model for defect diffusion. In this approach, we study the damage in the lattice as a function of dose and dose rate. A strong reduction in the total number of defects left in the lattice is observed for lower dose rates.
\end{abstract}

Amorphization of semiconductors by ion bombardment has been a subject of study for many years. However, the atomistic nature of amorphization, and in particular, damage accumulation is not yet understood. For heavy ion bombardment it is assumed that amorphization occurs by overlapping of disordered zones generated by single ion impacts, or heterogeneous amorphization [1]. This model is supported by HREM observations whch show highly disordered regions after low dose $100 \mathrm{keV} \mathrm{Bi}+$ implantation [2]. This is also in agreement with molecular dynamics simulations for self irradiation of Si [3] and irradiation with heavy ions [4]. In contrast, for light ion bombardment it is considered that amorphization occurs by accumulation of point defects: when a critical concentration of point defects is reached the lattice collapses and, consequently, a continuous amorphous layer is produced [5]. A linear increase of the number of defects produced is observed as a function of dose $[6,7]$ that has also been related to an increase in the lattice strain [8]. However, these simple models for amorphization can not explain recent results about ion beam induced amorphization at elevated temperatures [9]. In this case, the minimum dose for amorphization depends both on the temperature of the lattice and the ion flux. The final damage is the result of two competing effects: damage production and damage annihilation during ion irradiation. At low enough temperatures, when defects are not mobile, there is no dependence on the dose rate, as observed experimentally for irradiation at $70 \mathrm{~K}$ [10]. At higher temperatures a dependence on dose rate is observed, and this dependence seems to be more important for light ion bombardment [11].

Ion implantation in Silicon can be studied using the binary collision approximation, like in simulation models such as Marlowe [12] or TRIM [13]. These models give an accurate description of the depth profile of the implanted species. However, they do not include dose rate effects, i.e., the possible annihilation and clustering of defects between cascades. In order to understand the effect of intercascade annihilation during damage accumulation we couple molecular dynamics and Monte Carlo simulations. This approach allows a complete description of both the initial damage state, described by molecular dynamics, and the defect diffusion and annihilation between cascades, given by the Monte Carlo model [14]. 
We study the damage produced by the bombardment of silicon with heavy ions using molecular dynamics simulations. The simulation uses the Stillinger-Weber interatomic potential [15] coupled with the Universal potential for short range interactions [13]. Inelastic energy losses are introduced by the Lindhard model [16]. The system is coupled to a thermal bath in order to dissipate the energy deposited by the ion, and a maximum of $\sim 10^{6}$ atoms are simulated. Ion implantation of As and Pt in Silicon at energies between 3 and $25 \mathrm{keV}$ has been simulated. Each of these ions produces an amorphous region generated in the core of the cascade.

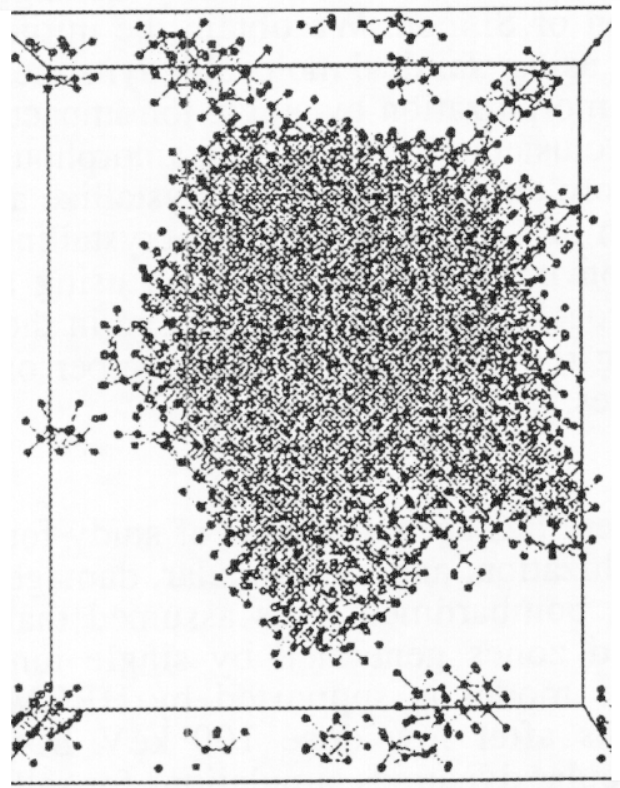

Figure 1. Amorphous pocket produced by a $25 \mathrm{keV} \mathrm{Pt}$ implant in Si, after 10ps
In figure 1 we present the amorphous pocket generated by a $25 \mathrm{keV}$ Pt impact on Silicon, after 10ps. The criteria to select an atom as amorphous is based on a time average of the bond angles and coordination number of each atoms. This is explained elsewhere [17]. We can observe that a large disordered zone is produced during the first few picoseconds of the cascade. However, the time regime for cascade overlap is of the order of $\mathrm{ms}$ to $\mathrm{s}$. Therefore, it is necessary to study the stability of the damage produced by these ions in order to understand dose rate effects on amorphization. Considering each of the amorphous pockets generated by different ion masses and energies as the starting point, we have studied the evolution of these pockets as a function of the temperature of the lattice. In figure 2 we present the number of amorphous atoms in the lattice as a function of time for different annealing temperatures. The initial configuration is an amorphous pocket generated by a $5 \mathrm{keV}$ As cascade in Silicon. Observe that the recrystallization does not proceed in an exponential way, but it includes large plateaus and sharp steps. This is in agreement with recrystallization models proposed for the growth of a planar amorphous-crystalline interface $[18,19,20]$. In these models recrystallization occurs by the production of a kink site that is able to migrate along [110] ledges in (111) planes. Each one of these defects can induce recrystallization of several atoms during its migration. In our simulations we find that amorphous pockets are less stable than a planar amorphous-crystalline interface, since they recrystallize at temperatures below the threshold for planar interface motion. This can be explained by the higher number of nucleation sites present in these amorphous pockets due to their irregular shapes, as compared to the case of a planar amorphous-crystalline interface, as proposed by Priolo et al [21]. From figure 2 we can extract an effective activation energy for recrystallization. The values obtained are $0.23 \mathrm{eV}, 0.37 \mathrm{eV}$ and $0.46 \mathrm{eV}$ for pockets containing 500,1500 and 4000 amorphous atoms respectively. Therefore, the stability of the amorphous pockets increases as the pocket size increases. From this result we can conclude that the minimum dose for amorphization must depend on the ion mass, since larger ions will produce larger amorphous pockets. And consequently, the maximum temperature for amorphization to occur must also depend on the ion mass. However, at room temperature and below the amorphous pockets seem to be stable, at least for the time scale of the simulations and in agreement with experiments [10]. 


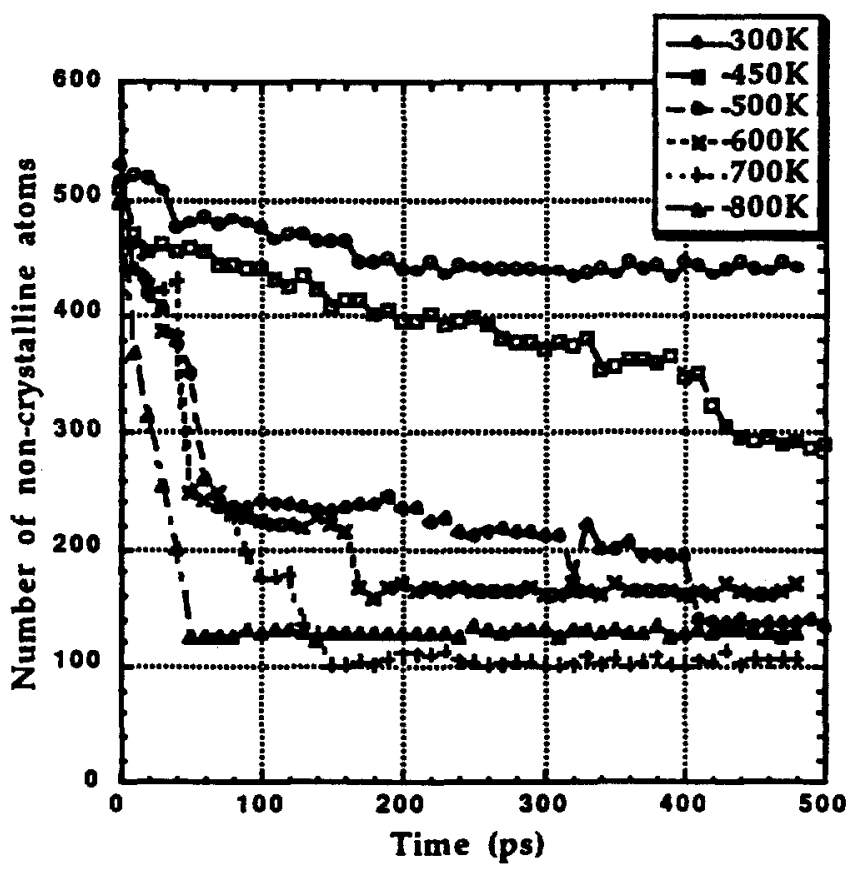

Figure 2. Number of amorphous atoms as a function of annealing time for different temperatures. The initial configuration is the result of a $5 \mathrm{keV}$ As implantation.
Currently, the decreasing size of semiconductor devices requires shallow junctions at depths of the order of $0.1 \mu \mathrm{m}$ or less. To achieve these, industry is moving towards lower energies for the implantation $(0.2 \mathrm{keV}-1 \mathrm{keV}$ for $B$ [22]) and lower doses $\left(-10^{15}\right.$ ions $\left./ \mathrm{cm}^{2}\right)$ and dose rates $\left(\sim 10^{14}\right.$ ions $/ \mathrm{cm}^{2}$ s). It is, therefore, important to understand how damage accumulation occurs at these very low energies. We combine the results obtained from molecular dynamics with Monte Catlo simulations of defect diffusion to study the effect of different dose rates in the final damage profile for irradiation of Si with $500 \mathrm{eV}$ B. The defects obtained from the molecular dynamics simulation are used as an input for the Monte Carlo model. These defects are allowed to migrate according to their diffusivities. The different energetics for vacancies, interstitials and dopants (boron in this case) are obtained from classical molecular dynamics simulations [23] and "ab initio" calculations [24]. Boron is considered to diffuse by coupling to an interstitial produced during the irradiation and undergoes a kick-out mechanism, as predicted by "ab initio" calculations [24]. In our simulations we considered room temperature, therefore boron diffusion is very unlikely. However, both vacancies and interstitials will be able to migrate at these temperatures, giving different results for different dose rates. The input parameters for this simulation are presented in Table I. Clusters larger than 5 have binding energies fitted to a function of the form: $\mathrm{Eb}_{\mathrm{V}}(\mathrm{N})=3.6-4.9\left(\mathrm{n}^{2 / 3}-(\mathrm{n}-1)^{2 / 3}\right) \mathrm{eV}$ and $\mathrm{Eb}_{\mathrm{I}}(\mathrm{n})=2.5-2.17\left(\mathrm{n}^{1 / 2}-(\mathrm{n}-1)^{1 / 2}\right) \mathrm{eV}$, for $\mathrm{V}$ and $\mathrm{I}$ of size $n$ respectively. The program is described in detail in ref. [14].

Table I. Parameters used for the Monte Cario simulation. Values for diffusivities and binding energies from classical molecular dynamics calculations [11].

\begin{tabular}{|c|c|c|c|c|c|}
\hline & DIFFUSIVITY $\left(\mathrm{cm}^{2} / \mathrm{s}\right)$ & $\begin{array}{c}\text { BINDING } \\
\text { ENERGY } \\
\text { SIZE 2 (eV) }\end{array}$ & $\begin{array}{c}\text { BINDING } \\
\text { ENERGY } \\
\text { SIZE 3 (eV) }\end{array}$ & $\begin{array}{c}\text { BINDING } \\
\text { ENERG } \\
\text { SIZE 4 (eV) }\end{array}$ & $\begin{array}{c}\text { BINDING } \\
\text { ENERGY } \\
\text { SIZE 5 (eV) }\end{array}$ \\
\hline VACANCY & 0.001 EXP(-0.43/KT) & 0.62 & 0.78 & 1.2 & 1.82 \\
\hline INTERSTITIAL & $0.01 . E X P(-0.9 / K T)$ & 1.6 & 2.25 & 1.29 & 2.29 \\
\hline
\end{tabular}

We perform a simulation of $500 \mathrm{eV}$ Boron implantation in Silicon at $350 \mathrm{~K}$. In figure 3 we show the final defect concentration in the lattice for a dose of $10^{15}$ ions $/ \mathrm{cm}^{2}$ at different dose rates. Observe that the total number of defects decreases as the dose rate 
decreases, since there has been more recombination both in the bulk and at the surface. At these very low energies the surface recombination has a very strong effect, since the defects are located very close to the surface. In figure 4 we plot the defects in the lattice as a function of dose for two different dose rates. From this figure we can see that the damage produced by these light ions do not accumulate linearly with dose, as it is in the case of heavy ion bombardment. Instead, there is a significant annihilation of damage in between cascades, and therefore, as the dose increases the recombination also increases, giving a sublinear increase in the amount of defects in the lattice. This effect is more pronounced for lower dose rates.

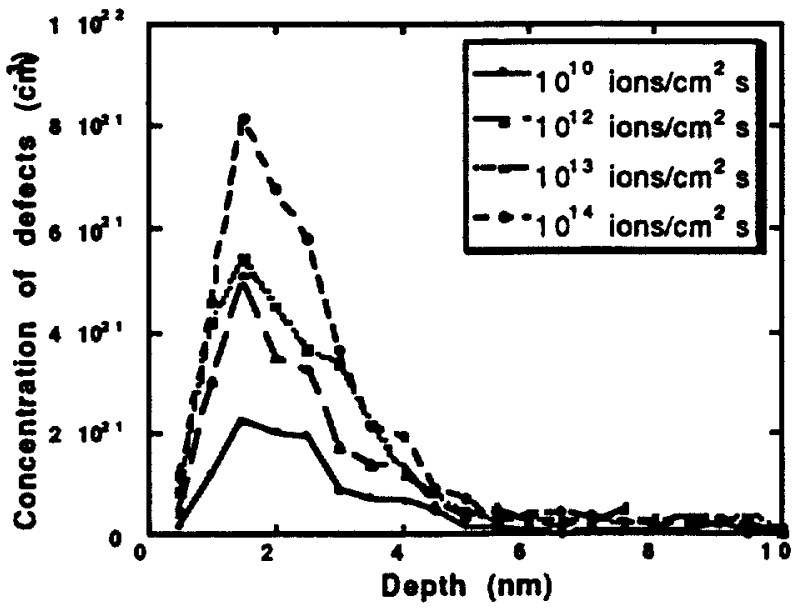

Figure 3. Concentration of defects in the bulk for different dose rates, for $500 \mathrm{eV}$ B implant in $\mathrm{Si}$, $10^{15}$ ions $/ \mathrm{cm}^{2}$.

by a single impact. Amorphization has to occur by the accumulation of point defects. The defects produced by light ions are small clusters or defects or isolated point defects, that are able to migrate, even at room temperature. Therefore, significant annealing between cascades is expected, and consequently a dependence on the dose rate for amorphization. Using molecular dynamics and Monte Carlo simulations we have shown that significant annihilation occurs between cascades and that the total defect concentration decreases as the dose rate decreases. This can also be observed in the dependence of the damage on the dose, which does not increase linearly as in the case of heavy ion implantation. For a complete simulation and understanding of light ion induced amorphization we are currently presforming simulations for higher energies and higher doses of B in Silicon.

\section{Acknowledgments}

This work was performed under the auspices of the U.S. Department of Energy by Lawrence Livermore National Laboratory under Contract No. W-7405-Eng-48. M. Jaraiz and G.H. Gilmer of Lucent Technologies provided theMonte Carlo code. 


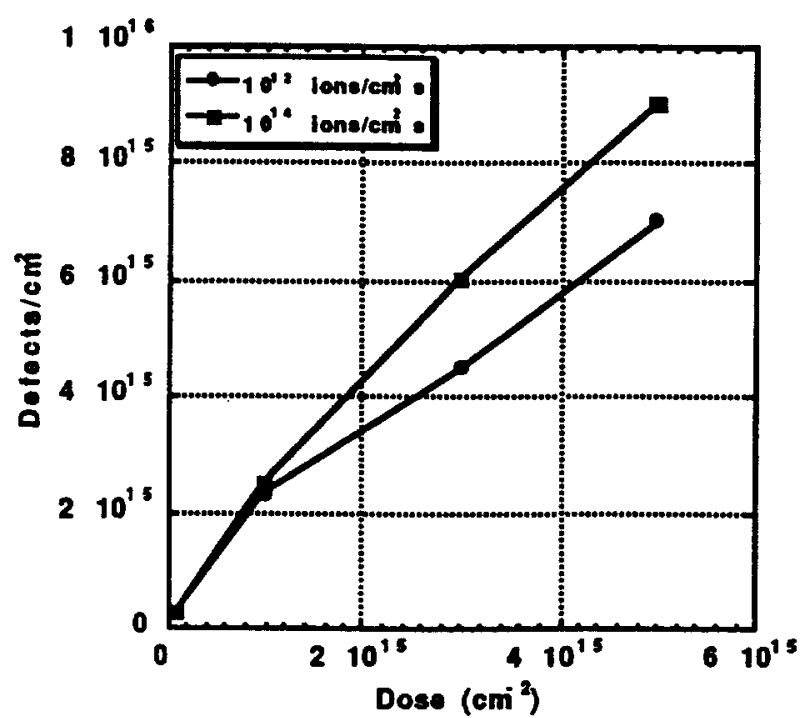

Figure 4. Damage as a function of dose for $500 \mathrm{eV}$ B implantation in Si at RT.

\section{References}

1. F.F. Morehead, Jr. B.L. Crowder, in Ion Implantation ed. F.H. Ewisen, L.T.Chadderton B. Gordon and Breach Science Publishers (1971) p 25

2. J. Narayan, O.S. Oen, D. Fathy and $\mathrm{O}$.W. Holland, Materials Letters 3, 67 (1985)

3. T. Diaz de la Rubia, G.H. Gilmer, Phys. Rev. Lett. 74, 2507 (1995) 4. M-J Caturla, L. A. Marques, T. Diaz de la Rubia and G.H. Gilmer, Phys. Rev. B (accepted for publication)

5. M.L. Swanson, J.R. Parsons, C. W. Hoelke, Rad. Eff. 9, 249 (1971)

6. G.Bai, M.A. Nicolet, J. Appl. Phys. 70, 6494 (1991)

7. O.W. Holland, S.J. Pennycook. G. L. Albert, Appl. Phys. Lett. 55, 2503 (1989)

8. R.D. Goldberg, J.S. Williams, R.G. Elliman, Nucl. Instrum. and Meth. B 106, 242 (1995)

9. C. Cellini, A. Carnera, M. Berti, A. Gasparotto, D. Steer, M. Servidori, S. Milita, Nucl. Instrum. and Methods B96, 227 (1995)

10. O.W. Holland, D. Fathy, J. Narayan, O.J. Oen, Rad. Eff. 90, 127 (1985)

11. S.Tian, S-H Yang, S. Morris, K. Parab, F. Tasch, D. Jamenitsa, R. Reece, B. Freer, R.B. Ximonton, C. Magee, J. Electrochem. Soc. 142, 3215 (1995)

12. M.T. Robinson and I.M. Torrens, Phys. Rev. B9, 5008 (1974)

13. J.F. Ziegler, J.P. Biersack, U. Littmark in The stopping and Range of Ions in Solids, Vol.1 of The Stopping and Range of Ions in Matter, ed. J.F. Ziegler (Pergamon, New York, 1985) p. $25 \mathrm{ff}$

14. M. Jaraiz, G. H. Gilmer and T. Diaz de la Rubia, Appl. Phys. Lett. 68, 409 (1996)

15. F.H. Stillinger and T.A. Weber, Phys. Rev. B31, 5262 (1985)

16. J. Lindhard and M. Sharff, Phys. Rev. 124, 128 (1961)

17. L. A. Marques, M-J Caturla, G.H. Gilmer, T. Diaz de la Rubia, J. Appl. Phys. 80, 6160 (1996)

18. F. Spaepen, D. Tumbull in Laser Solid Interactions and Laser Processing, ed. S.D.

Ferris, H.J. Leamy, J.M. Poate, Mat. Res. Soc., Boston, 1978

19. G.-W. Lu, E. Nygren, M.J. Aziz, J. Appl. Phys. 70, 5323 (1991)

20. J.S. Williams, R.G. Elliman, Phys. Rev. Lett. 51, 1069 (1983)

21. F. Priolo, A. Battaglia, R. Nicotra, Appl. Phys. Lett. 57, 768 (1990)

22. M.A. Foad, J.G. England, S. Moffatt, D.G. Armour, Proceedeings for the IIT'96 conference

23. G.H., Gilmer, T. Diaz de la Rubia, M. Jaraiz, D. Stock, Nucl. Instrum. and Methods B102, 247 (1995)

24. J. Zhu, T. Diaz de la Rubia, L. Yang, C. Mailhiot and G. H. Gilmer, Phys. Rev. B 54, 4741 (1996) 


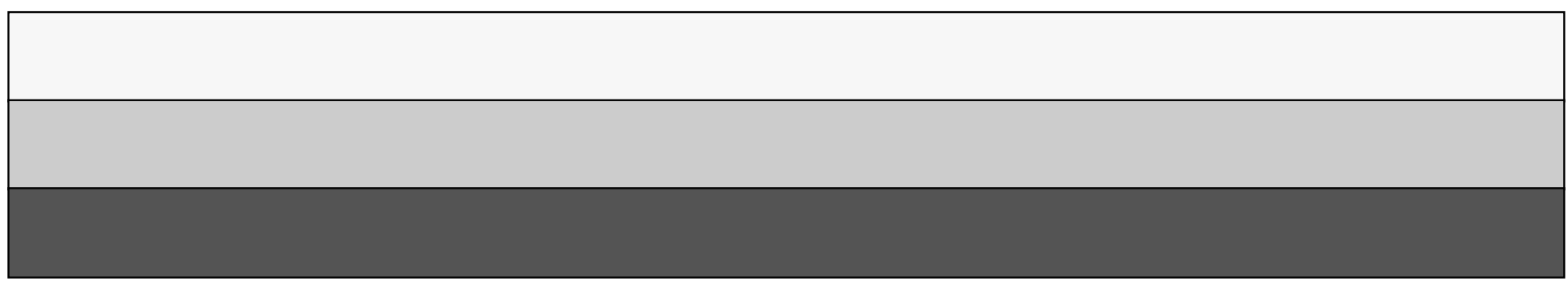

